\title{
What evidence exists on the relationship between agricultural production and biodiversity in tropical rainforest areas? A systematic map protocol
}

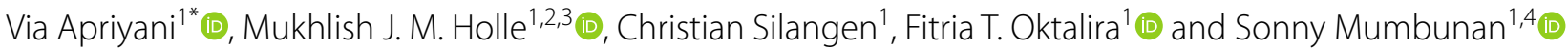

\begin{abstract}
Background: Agriculture produces food for billions of humans and creates livelihoods for farmers. However, the current food production systems, driven by the increasing food demand and the ever-growing human population, are undermining ecological resources, primarily those related to biodiversity. Accordingly, agricultural production in tropical rainforest countries has been a trade-off, as regions harbor high biodiversity while also being pressured by agricultural land expansion. Consequently, threats to biodiversity are inevitable and will likely affect the ecosystem service provisions necessary for the agricultural process. Presently, no study reviews and maps the evidence of relationships between biodiversity and agriculture in the tropical rainforest landscape. Therefore, such a study is necessary to identify the knowledge gaps and provide scientific evidence to the relevant policymakers for safeguarding biodiversity within agricultural policies. This study aims to collect available published literature that evaluates the relations of agricultural production and biodiversity. We will focus on the agriculture and priority crops in the countries producing the commodities situated in the tropical rainforest landscape.

Methods: Generic search terms derived from research question elements will be used to search relevant articles. These terms are in English, and the searches will encompass global tropical rainforest countries. Peer-reviewed and gray literature articles retrieved from search engines and databases will be screened first using the title and abstract and second at the full-text level. The latter screening process will involve data coding to retrieve relevant characteristics from each eligible study and finally collate these characteristics into an evidence map, which will provide a current state of knowledge and further support evidence-informed policy formulation. The map presentation in the final report will also be complemented by a narrative synthesis explaining the trends, pinpointing the knowledge gluts and gaps, serving relevant information, and searchable databases for associated stakeholders.
\end{abstract}

Keywords: Food production, Rainforest, Farming practices, Agroecosystem, Natural ecosystem, Flora, Fauna, Services, Disservices, Evidence-based study

*Correspondence: via.apriyani@gmail.com

${ }^{1}$ Research Center for Climate Change, Faculty of Mathematics and Natural Sciences, University of Indonesia, Depok, Indonesia Full list of author information is available at the end of the article

\section{Background}

Tropical forests occupy merely 45 percent of the total global forest area [1] or approximately 13 percent of the global land area [2] but provide habitats for two-thirds of the global terrestrial biodiversity [3]. Nevertheless, the degradation of tropical forests is a leading factor in the depletion of global biodiversity [4]. Furthermore, original author(s) and the source, provide a link to the Creative Commons licence, and indicate if changes were made. The images or other third party material in this article are included in the article's Creative Commons licence, unless indicated otherwise in a credit line to the material. If material is not included in the article's Creative Commons licence and your intended use is not permitted by statutory regulation or exceeds the permitted use, you will need to obtain permission directly from the copyright holder. To view a copy of this licence, visit http://creativecommons.org/licenses/by/4.0/. The Creative Commons Public Domain Dedication waiver (http://creativeco mmons.org/publicdomain/zero/1.0/) applies to the data made available in this article, unless otherwise stated in a credit line to the data. 
deforestation is driven mainly by agriculture [5], especially in tropical regions [6]. Almost 6 million hectares of tropical forests have been planted for agricultural purposes [7].

Managing tropical landscapes sustainably remains a substantial challenge [8]. On the one hand, conserving tropical biodiversity is undoubtedly important as tropical regions are prioritized global areas for conservation and restoration [9-12]. On the other hand, the agricultural landscape is important because it supplies foods to sustain rural livelihoods and nourish the human population [8]. As such, the demand for agricultural production to provide food and generate income is rapidly increasing in conjunction with human population growth. As the human population is projected to reach 11 billion this century [13], an increase in agricultural production is necessary primarily by expanding agricultural land.

However, as agriculture has developed quickly globally, concern about the impact of agriculture on the environment is increasing. For example, 99\% of the global consumptive freshwater footprint is used for agriculture [14], while water itself is essential for human beings. Moreover, maximizing monoculture plantations and crop protection from pests in agricultural production requires crop interventions, such as pesticide use [15]. Hence, even though pest management can be naturally provided by ecosystem service-related biodiversity $[16,17]$, intervention using chemical pesticides is preferred given the costs, results, and effectiveness [18]. Consequently, the direct effects on wild species important for agricultural production are unavoidable. It seems likely that there is an endless loop where crop interventions create side effects on the environment, while more intense crop interventions are required in an altered environment. Hence, integrating natural ecosystem services into agricultural production is key to terminating the loop and sustaining agriculture $[16,19]$.

Fewer environmental regulations are one of the factors driving driven forest-rich tropical countries to increase agricultural demand [20]. Accordingly, regulations and policies for biodiversity and nature-friendly agriculture require methods and indicators for assessing the effects on both biodiversity conservation and function [15]. Currently, sustainable agriculture certification standards can integrate biodiversity protection and social justice despite the uncertainty in maintaining long-term sustainability. Good governance and regulatory frameworks are required to replace imperfect certification standards [19]. To establish relevant policies for agriculture and biodiversity sustainability, the Organization for Economic Co-operation and Development (OECD) has developed an Agri-Biodiversity Framework consisting of essential indicators to assess the link between agriculture and biodiversity [21]. However, this framework is not fully relevant in the tropical context and does not fully apply to tropical agriculture and biodiversity relationships. Therefore, understanding the bidirectional linkages between tropical agricultural production activities and biodiversity and collating this evidence are necessary. This approach will provide clearer information and identify the cutting-edge research on the matter; additionally, it could help inform decision-makers in transforming crop production systems in tropical agriculture.

Biodiversity and agricultural production can have a bidirectional relationship. There are biodiversity impacts on agricultural production and agricultural production impacts on biodiversity.

\section{Impacts of biodiversity on agricultural production}

Agroecosystems rely on the ecosystem services that natural ecosystems offer, such as pollination, pest control services, soil structure, and fertility regulation, and hydrological services $[16,22]$. These ecosystem services are associated with biodiversity [23]. The role of biodiversity in improving agricultural production used to be neglected despite its high economic value. For example, the production of more than $75 \%$ of globally important crops and $35 \%$ of the food produced rely on pollination services [24]. The global value of crop pollination services is estimated to range widely from US $\$ 195$ billion to $\sim$ US\$387 (US\$267-657) billion annually [25]. However, pesticide misuse potentially reduces the number of pollinators in agroecosystems [26] and has economic impacts. Additionally, biodiversity can also reduce agricultural productivity through ecosystem disservices, such as pest damage, competition for water from other ecosystems, and competition for pollination [22]. Crop pests, pathogens, frugivores, and seed eaters are some of the components of biodiversity that could reduce agricultural production. Similar to ecosystem services, ecosystem disservices are triggered by the mismanagement of agroecosystems. Excessive pesticide use is likely to enable pest outbreaks and pesticide resistance [22]. Therefore, the ecosystem services and disservices provided by biodiversity are determined by agroecosystem management.

\section{Impacts of agricultural production on biodiversity}

Although highly relying on the ecosystem services provided by the biodiversity components, some agricultural practices negatively affect biodiversity, one of which is through habitat loss and fragmentation [27]. Moreover, among all other human activities, farming has created greater impacts on biodiversity [5], especially in tropical regions where most agricultural land is obtained by destroying tropical forests $[6,20]$. Further, almost 6 million hectares of tropical forests were converted for 
agricultural purposes annually in 1990 [7]. For example, forest conversion into croplands, especially for oil palm and rubber, drives the ongoing biodiversity crisis in Southeast Asia [28]. However, sustainable tropical landscape management could also help biodiversity thrive in agroecosystems. As such, designing well-managed agricultural landscapes can support many types of wild biodiversity, with neutral or even positive effects on agricultural production and human wealth [29]. Therefore, effective management of human-modified landscapes determines the fate of tropical forest biodiversity [3], whether biodiversity coexists with agroecosystems or vice versa.

\section{Framework development}

We developed a new framework called the Tropical Agriculture and Biodiversity Framework (TABF) [30] adapted from the OECD's agriculture-biodiversity framework [21]. The OECD framework is an existing comprehensive framework containing a set of agri-environmental indicators that assess agri-biodiversity relationships and the socioeconomic interactions between farming and biodiversity to achieve sustainable agriculture.

Similar to the OECD framework, in building the TABF, a series of meetings and workshop series were conducted by involving experts from various relevant universities or institutions in Indonesia and the UK. The newly generated framework, TABF, consists of five indicators related to agriculture and biodiversity, as well as external drivers, i.e., socioeconomic factors and disturbances (Fig. 1, Table 1). As external factors in the TABF, socioeconomic factors and disturbances interact with the indicators to different extents. Hence, these will be explained by merging them into the relevant indicators. Below is the explanation of each indicator as well as the important elements included in it.

\section{Tropical agricultural production base}

An agricultural production base is defined as the compulsory necessity for running agricultural production.

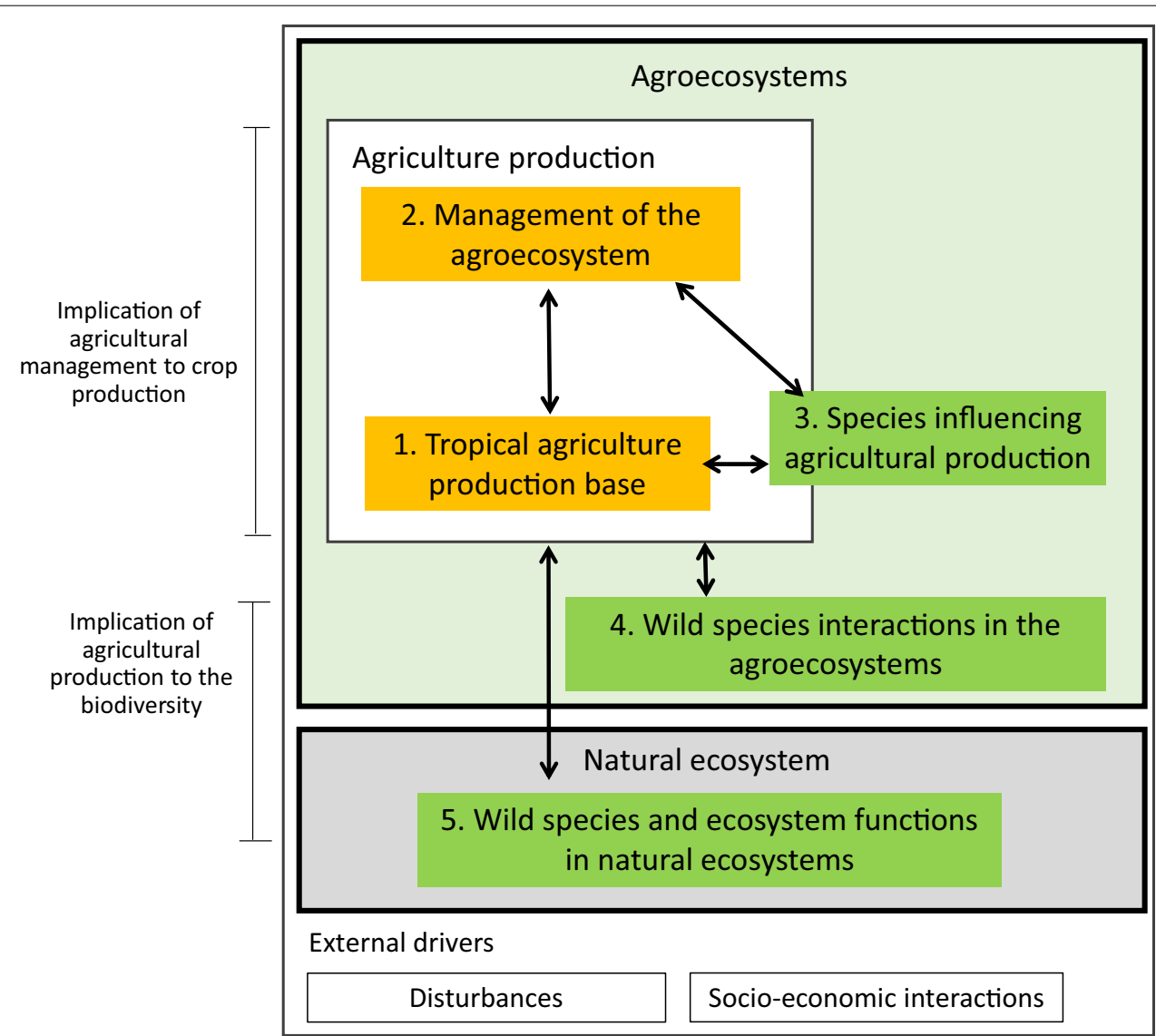

Fig. 1 Schematic diagram of the tropical agriculture and biodiversity framework (TABF). This figure illustrates the five proposed indicators and the external drivers that influence tropical agriculture and biodiversity. The indicators are distinguished by colors; orange boxes refer to components of agriculture, and green boxes refer to the components of biodiversity. These components are affected by external drivers of socioeconomic interaction and disturbances. See [30] 


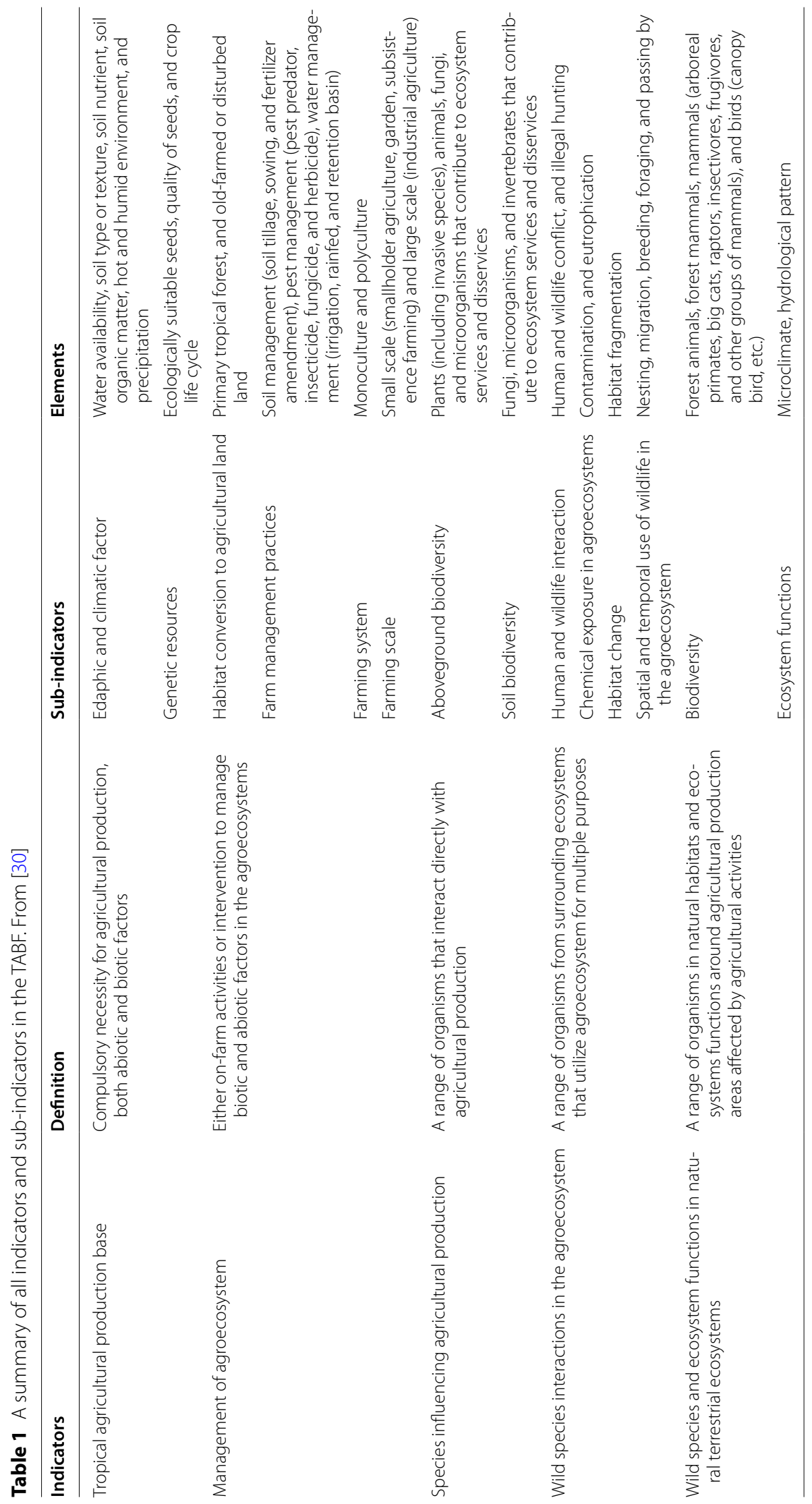


The tropical agricultural production base emphasizes the basic capitals of agricultural production that determine whether agriculture can produce a certain crop yield. This should be considered for maximizing crop yield potential while becoming a subject of agricultural production management. There are two main components of this indicator: edaphic and climatic factors and genetic resources.

\section{Management of the agroecosystem}

This is categorized as a group of indicators that signify habitat quantity and quality. Habitats in this study refer to agroecosystems and the surrounding natural ecosystems. For this indicator, we found the need to include information on land or natural ecosystem conversion to agricultural land. Furthermore, practices in agricultural management (i.e., soil, pest, and water) and farming systems are included since they reflect human interventions to biotic and abiotic resources.

\section{Species influencing agricultural production}

Identifying and understanding wild species in agricultural production will help us to better understand which taxa play significant roles in agroecosystem processes (both positive and negative) and how they interact within the agroecosystem. This includes how biodiversity affects agricultural management as well as agricultural production. Intensive agriculture production activities at the local scale have significant implications on surrounding wild species of flora and fauna (ecology) as well as economic impacts. Moreover, species capable of adapting to the agricultural environment as well as their species composition may be limited by management practices including soil, pest, and water management (as mentioned in the previous section). Exploring the interaction pathways between biodiversity and agricultural production is the combination of many key elements within the agroecosystem.

\section{Wild species interactions in agroecosystems}

Agroecosystems have direct and indirect impacts on natural ecosystems. Wildlife that lives adjacent to agricultural land is affected by these human-modified ecosystems. With proper management, humans and wildlife can coexist together and utilize closely entangled areas. In the TABF, we will incorporate how agroecosystems support the species that require and use these agroecosystems and, conversely, the disruption caused by poorly managed agroecosystems towards these species. We also include the wildlife status (from the most concerned to the least concerned), but generally, we want to see how wild species in the agroecosystems use and require the aforesaid. The proposed sub-indicators include the spatial and temporal uses of wildlife in the agroecosystems, human and wildlife interactions, chemical exposure in the agroecosystem, and habitat change.

\section{Wild species and ecosystem functions in natural ecosystems}

This particular indicator includes how agroecosystems support the species in the natural habitat and the negative impacts that on-farm and agroecosystem management actions cause. In general, we want to see what relationships exist between all kinds of species that use natural habitats and agroecosystems. In addition to the diversity of plants and animals at the species level, we look at the ecosystem level and the functions attached to it.

\section{External drivers}

External drivers refer to disturbances and socioeconomic interactions. Agricultural practices with the ecological dynamics occurring therein greatly depend on environmental conditions ranging from climate varieties, temperature fluctuations, fires, precipitation, and droughts. Regarding the disturbances, we focus on natural disturbances independent of agricultural practices: volcanic eruptions, hurricanes, and disease outbreaks among others. These natural disturbances, directly and indirectly, affect the sustainability of agricultural practices and biodiversity in the agroecosystem. In addition to ecological approaches in linking agriculture and biodiversity, factors such as social, economic, and policy are important in determining land-use decisions and farmers' attitudes towards agricultural practices, which in turn affect biodiversity. Socioeconomic interactions include land ownership, farmers' knowledge, and local wisdom. Governmental policies, such as national food security targets and transmigration programs, should also be considered.

The ultimate goal of developing the TABF is to conduct an evidence synthesis study (i.e., a systematic map and systematic review). In this paper, we focus on a systematic map study to collate the current state of evidence that shows the bidirectional linkages between agricultural production and biodiversity in the tropical rainforest landscape.

We will operationalize the framework into an evidence map matrix. Two evidence matrices will be built, one focusing on how agricultural practices affect biodiversity (Map 1) and the other focusing on how biodiversity contributes to agricultural production (Map 2). These matrices will be established after the review process and will be presented in the evidence map result report.

Furthermore, regarding the incorporation of the external drivers into these relationship map matrices, first, we selected the most salient and important drivers that influence agriculture and biodiversity. Second, we 
Table 2 Selected indicators and sub-indicators of the TABF for systematic Map 1, the relationship between tropical agricultural production and biodiversity

\begin{tabular}{ll}
\hline Indicators & Key search terms derived from sub-indicators \\
\hline $\begin{array}{l}\text { Agricultural components as the exposure } \\
\text { Tropical agricultural production base }\end{array}$ & Environmental factors \\
Management of the agroecosystem & Genetic resources \\
& Land conversion \\
& Socioeconomic factors \\
& Disturbances \\
Siodiversity components as the outcomes & Soil management \\
Species influencing agricultural production & Pest management \\
Wild species interactions in the agroecosystem & Water management \\
& Land ownership \\
& Crop diversification \\
& Aboveground biodiversity \\
Wild species and ecosystem functions in natural ecosystems & Soil biodiversity \\
& Spatial and temporal uses of wildlife in the agroecosystems \\
Human and wildlife interaction
\end{tabular}

determined which indicators in the TABF were relevant to explain each driver. Socioeconomic interactions will likely be relevant to indicator two (management of agroecosystems), while disturbances will affect most indicators to different extents. Therefore, by integrating these drivers into the relevant indicators, we expect to see how these drivers interact and influence agricultural practices and biodiversity.

Additionally, for a relationship map of agricultural impacts on biodiversity, the included sub-indicators are displayed in Table 2. The included sub-indicators that describe the linkages between biodiversity and tropical agriculture are shown in Table 3. For data collection purposes, we modify the terminology of each sub-indicator with the relevant and illustrative key search terms.

\section{Objective of this review}

This systematic map aims to assemble and map the present state of evidence that describes the linkages of agricultural production activities and biodiversity in tropical rainforest landscapes. Moreover, we are particularly interested in the bidirectional relationships between tropical agricultural production and biodiversity.

In light of the above, undertaking a systematic map of evidence on those two subjects is necessary, as no such study has yet been performed, particularly in tropical rainforest countries, where the majority of important,
Table 3 Indicators and sub-indicators of the TABF included in systematic Map 2, the relational evidence of the biodiversity implications to tropical agriculture

\begin{tabular}{ll}
\hline Indicator & $\begin{array}{l}\text { Key search terms } \\
\text { derived from sub- } \\
\text { indicators }\end{array}$ \\
\hline $\begin{array}{c}\text { Biodiversity components as the exposure } \\
\text { (based on services and disservices) }\end{array}$ & Shelter \\
& Microhabitat \\
Litter sources \\
Invasive species \\
Pollinator \\
Tropical agricultural production base & Pest predators \\
Agricultural components as the outcomes & Decomposer \\
Tropical agricultural production base & Avifauna and insects \\
Management of the agroecosystem & Terrestrial mammals \\
Genetic resources \\
\end{tabular}


high-economic value crop commodities are produced [31]. Furthermore, almost all the systematic map papers on the related subject we found undertaking this review focused on a very narrow scope of agricultural matters and were not specific to the rainforest landscapes. For instance, Van Der Meer et al. [15] mapped the evidence of fruit orchard impacts on biodiversity indicator species groups in temperate climates; Shin et al. [32] conducted a systematic map study on agroforestry practices in the Asia-Pacific region.

Hence, we aim to conduct a systematic map study that captures agricultural activities at the multi-spatial scale and identify their relations with biodiversity in tropical agroecosystems and natural ecosystems. We will include the diversity of flora and fauna at the species and ecosystem levels along with the ecosystem services and disservices they provide to agricultural activities.

By doing so, it is expected that the evidence maps of agriculture-biodiversity and the vice versa relations in tropical rainforest contexts will provide a clearer overview of the current state of research and highlight the trends on that subject. Additionally, the evidence map outcome would help to inform related stakeholders to better develop science-based policies of sustainable food production.

The primary research question that will overarch this systematic map study is therefore as follows:

What evidence exists on how tropical agricultural production activities and biodiversity influence one another?

Following that, the secondary research questions are as follows:

1) What is the state of evidence for tropical agricultural production and its relations to biodiversity in terms of the quantity of articles, study types, commodity types, and geographical locations?

2) What evidence exists regarding the impacts of tropical agricultural production bases and the management of agroecosystems on biodiversity?

3) What evidence exists regarding the impacts of biodiversity on tropical agricultural production?

\section{Elements of the primary question}

Given the bidirectional linkages we intended to assess, we identified two different key elements of the primary question based on secondary research questions two and three outlined as follows:

2) What evidence exists regarding the impacts of tropical agricultural production bases and the management of agroecosystems on biodiversity?

Population: Tropical rainforest areas.
Exposure: Tropical agriculture production base and management of the agroecosystem.

Comparator: No agriculture (spatial) or before agriculture (temporal).

Outcome: Changes in indicators (e.g., species richness, abundance, composition, density) of biodiversity in agroecosystems and natural ecosystems.

3) What evidence exists regarding the impacts of biodiversity on tropical agricultural production?

Population: Agriculture producing priority crop commodities in tropical rainforest countries.

Exposure: Existence of biodiversity (e.g., species richness, abundance, composition, and density) and mediated functionality (i.e., ecosystem services/disservices) in agroecosystems.

Comparator: Farms with less biodiversity mediating functionality.

Outcome: Changes of tropical agricultural production base (i.e., availability of edaphic and climatic factors and availability and suitability of crop varieties) and changes in the suitability of the agroecosystem management (i.e., management of soil, water, pest, and crop diversification).

\section{Methods}

This study will follow guidance on conducting a systematic map of evidence according to the Collaboration for Environmental Evidence [33].

\section{Searching for articles Key search terms}

We established generic key search terms using the English language to answer the research questions. The initial search terms generated were related to elements of the primary research questions: "tropical rainforest agriculture" AND "biodiversity". These terms were then developed for the establishment of search strings by looking at the synonyms or alternative words commonly used within the topics. We are aware that all search terms produce some irrelevant articles; however, we would like to ensure that the search strings capture as comprehensive as possible articles relevant to the research questions by developing and refining the strings through iterative pilot testing in Scopus.

Moreover, as we are interested in observing the distinguished nature of bidirectional relations between tropical agriculture and biodiversity, we proposed two different exposure and outcome terms according to the secondary research questions as follows:

For the second secondary research question: 
Map 1

Subject terms "rain forest" OR "rainforest" AND "tropic"” OR "humid" OR "moist" OR "equator".

Exposure terms "agri"” OR "agro"” OR "farm"” OR "crop*" OR "horticulture" OR "food produc*" OR "cultivat"” OR "yield produc*".

Outcome terms "species" OR "wildlife" OR "plant" OR "plant"” OR "fauna" OR "flora" OR "animal" OR "insect" OR "insect" " OR "microb" " OR "microorgani" ter" OR "fung" "mammal" OR "bird" OR "livestock" OR "invasi"” OR "divers" OR "biodiversity" OR "group".

Adjacent to "rich" OR "rich" OR "even" OR "abundan"” OR "change" OR "dynamic" OR "functio" OR "conflic" " OR "interac" OR "decrease" OR "reduc" OR "loss" OR "contraction" OR "increase" OR "gain" OR "grow" OR "restor" OR "expansion" OR "effec" "relatio" " OR "influenc".

For the third secondary research question:

\section{Map 2}

Subject terms "rain forest" OR "rainforest" AND "tropic*" OR "humid" OR "moist" OR "equator".

Exposure terms "role" OR "effect" OR "impact" OR "contribution" OR "function" OR "relationship".

Adjacent to "species" OR "wildlife" OR "plant" OR "plant" OR "fauna" OR "flora" OR "animal" OR "insect" OR "insect*" OR "microb*" OR "microorgani*" OR "bacter" ${ }^{*}$ " OR "fung" " OR "invertebrate" OR "pollinat" "mammal" OR "bird” OR "livestock" OR "invasi*" OR "divers"” OR "biodiversity" OR "group*".

Outcome terms "agri*" OR "agro" OR "farm" OR "crop*" OR "horticulture" OR "food produc*" OR "cultivat" OR "yield produc*".

Adjacent to "management" OR "practice" OR "soil" OR "water" OR "irrigation" OR "pond” OR "pest” OR "pesticide" OR "weed" OR "farming system" OR "monoculture" OR "polyculture" OR "agroforest" OR “intercrop" "small-scale" "large-scale" OR "industr"”.

The above exposure and outcome search strings were applied in the tested database and will be operated in the targeted databases to search for articles. Notably, as the different database sources might have different search functionalities, modest string modifications using the Boolean operators may be necessary. The record of the tested search strings that also represent the result of scoping exercise can be found in Additional file 1. In Scopus, 84 and 52 search strings for Map 1 and Map 2 were examined respectively. The final strings tested in Scopus with year limitation > 2015 for Map 1 resulted in 432 hits, and Map 2 resulted in 219 hits. The search strings tested in Scopus sufficiently resulted in hits assessing the impacts of tropical agriculture on biodiversity, and conversely, the impacts of biodiversity on tropical agriculture. The use of "rainforest" and "tropic" terms combined with its synonyms and syntax features helped narrow the results captured in the test search. The hits capture articles that quantify the variety of exposures and measured outcomes listed in our eligibility criteria. The agricultural exposure types captured in the test search of Map 1 including land-use gradients, land conversion into crop plantations, crop diversification (e.g. monoculture and agroforestry), pest management, and soil management. The types of biodiversity outcomes measured include soil biodiversity (e.g. microbe, fungi, and dung beetle), and aboveground biodiversity (e.g. butterfly, bat, epiphyte, and mammal). The test search for Map 2 results biodiversity exposures ranging from genetic resources, crop varieties, trees as litter source, pest predators, and pollinators. Examined agricultural outcomes include ecologically suitable seeds (e.g. drought resistant cultivars), soil organic matter, soil water content, and pest control.

\section{Estimating the comprehensiveness of the search}

To examine the sensitivity and whether these search strings cover relevant papers, we ran the strings against a set of test libraries (Additional file 2). The test libraries, which were independent from the test search results, were identified through asking researchers judged by our understanding on the conceptual framework and eligibility criteria and by looking at bibliographic list from currently available review studies on similar topics. All the citations listed in the test library were captured by using the keywords we established in the test search.

\section{Searching the literature \\ Publication bibliographic databases}

We will undertake a literature search process using publication databases and organizational websites. The publication databases used to collate peer-reviewed articles, including multidisciplinary and publisher databases, are described as follows:

1. Multidisciplinary bibliographic sources: including Scopus, Web of Science Core Collection list of indexes provided in Additional file 1, Directory of Open Access Journals (DOAJ), Science Publishing Groups, AGRICOLA National Agricultural Library, and Citation Database, AGRIS Agricultural Science and Technology Information Systems

2. Publisher databases: Elsevier's ScienceDirect, Wiley InterScience, and Springer Link 


\section{Gray literature}

In addition to peer-reviewed articles, we decide to include gray literature, not only because it is suggested by the CEE guidelines [33] but also because it is useful in minimizing publication bias and collecting relevant articles probably not published in common peer-reviewed bibliographic sources [34]. However, as searching and assessing gray literature can be time- and resource-consuming [35], we will search articles from the obtained gray literature databases relevant to the study objectives. Relevant gray literature articles will be compiled, screened, and synthesized as peer-reviewed articles.

The types of gray literature included working papers, proceedings, theses, dissertations, policy briefs, and reports [23]. This literature will be searched through organizational databases (i.e., universities repositories, nonprofit organizations, and governmental institutions) and subject-related particular websites, as shown in Table 4.

\section{Web-based search engines}

Google Scholar will be utilized to supplement the search process, expected to increase the chance of obtaining relevant papers that might not yet be captured in the other publication sources used in this study [36].

Accordingly, article searching in the peer-reviewed and gray literature mentioned above will be confined by the time of publication. Based on our interest, we will account only for articles published in the years $\geq 2000$. There are several considerations when deciding the cutoff date for this study. First, we want to get enough papers to synthesize evidence and draw a conclusion by having a span of 20 years. Second, the result of the search test was limited to years before 2000 (1979-1999) in Scopus, which produced few articles. The paucity of articles published in these periods may have been influenced by article digitization technology, which was not as advanced as the year 2000 and beyond. Moreover, most of these results did not meet our eligibility criteria, either in terms of the exposure/outcome or the type of article.

\section{Bibliographic management}

The articles obtained from the database searching will be assembled in Mendeley, a reference management software helpful in assisting the reviewers with organizing hundreds of thousands of references so that eligibility screening can be performed efficiently.

\section{Article screening and study inclusion criteria Eligibility screening}

Collected citations and articles from the databases will be stored in the Mendeley desktop library. The next process will be assisted by Colandr, a machine learning software developed by Cheng et al. [37]. It consists of two systems: Firstly, the user screens the titles and abstracts. Results of the first screening that can be included, excluded, or

Table 4 List of organizational databases to be used for searching gray literature

\begin{tabular}{|c|c|}
\hline Organizational databases & Web URL \\
\hline Bioversity International & https://www.bioversityinternational.org/ \\
\hline Center for International Forestry Research (CIFOR) & https://www.cifor.org \\
\hline Climate Change Agriculture and Food Security (CCAFS) & https://ccafs.cgiar.org/publications/ \\
\hline Consultative Group for International Agricultural Research (CGIAR) & https://ciat.cgiar.org/publications/ciat-library-resources/ \\
\hline Ecoagriculture Partners & https://ecoagriculture.org/resources/publications/ \\
\hline Food and Agricultural Organization & https://www.fao.org \\
\hline $\begin{array}{l}\text { French Agricultural Research and International Cooperation Organization for The Sustain- } \\
\text { able Development of Tropical and Mediterranean Regions }\end{array}$ & www.cirad.fr \\
\hline International Development Research Centre (IDRC) & https://www.idrc.ca/en \\
\hline International Food Policy Research Institute Library (IFPRI) & http://library.ifpri.info/ \\
\hline International Institute of Tropical Agriculture (IITA) & https://www.iita.org/knowledge/publications/ \\
\hline International Impact Initiative (3ie) & https://www.3ieimpact.org/evidence-hub/publications \\
\hline International Institute for Environment and Development (IIED) & https://pubs.iied.org/ \\
\hline South Asian Network for Development and Environmental Economics (SANDEE) & http://www.sandeeonline.org/publicationdisp_main.php \\
\hline The Economics of Ecosystems and Biodiversity & http://teebweb.org/publications/ \\
\hline TROPENBOS Sustainable Land Use & $\begin{array}{l}\text { https://www.tropenbos.org/resources/publications? } \\
\text { theme_title=Sustainable+land+use }\end{array}$ \\
\hline Tropical Agricultural Research and Higher Education Center (CATIE) & http://www.catie.ac.cr/en/ \\
\hline World Resources Institute (WRI) & https://www.wri.org/publication \\
\hline CABI Agriculture and Bioscience & http://www.cabdirect.org/ \\
\hline
\end{tabular}


unknown will be learned by machine learning to rank the remaining and unscreened citations based on their relevance. The more machine learning is trained, the more it learns and puts the most relevant citations at the top of the list. At the data extraction in system 2, machine learning is trained from the first 25 pdf documents manually screened and categorized by users. The model will learn relevant keywords and henceforward will automate the data extraction process by displaying only keywords in the category that the user needs. Users can label the recommended information by accepting, rejecting, and skipping them in system 2 .

We will import the collected articles into Colandr, and the software will remove duplicates. Subsequently, the articles will be screened first at the title and abstract levels by two reviewers. The reviewers will screen and evaluate the same set of articles independently but will ultimately compare the results to test the consistency. If there is a dissensus between the reviewers, a discussion to reach an agreement over the contentious article will be performed before the full-text screening is conducted.

The following stage will be the second screening at the full-text level. The full text will be reviewed against the same inclusion and exclusion criteria as in the firststage screening. To increase consistency and reliability, reviewers will also be responsible for dual and independent screening of articles. The excluded articles will be reported in additional files in the narrative report with justifications for excluding them. Articles that pass fulltext screening will be extracted to answer the research questions. The screening and extraction steps are applied to produce Map 1 and Map 2, respectively. To test Colandr's accuracy at the data extraction stage, we will pick at least 25 articles (outside the first 25 pdf manuallyextracted documents) highly relevant to the study and compare whether Colandr's label recommendation match with these 25 papers.

\section{Eligibility criteria}

The eligibility criteria explained below are used to screen the articles that explain the impacts of tropical agriculture on biodiversity and the opposing relations of biodiversity to agriculture. Hence, we proposed different exposures, outcomes, and comparators to explain those bidirectional linkages. The remaining elements, such as populations and study design, were the same.

\section{Relevant populations}

The key criteria we will use in this population relate to agricultural activities that produce priority crop commodities in tropical rainforest countries. Among the top priority crop commodities we retrieved from the FAO list (based on its average gross production value) are dominated by food crops (Additional file 3): rice, soybeans, maize, sugar cane, wheat, oil palm, oil palm fruit, cassava, bananas, seed cotton, vegetables, mangoes, mangosteens, guavas, potatoes, cotton lint, tomatoes, oranges, coffee, yams, rubber, beans, onions, plantains, chilies and peppers, okra, groundnuts, pineapples, chickpeas, papaya, avocado, lychees, durian, rambutan, passionfruit, coconuts, grapes, cacao, clove, and tobacco [38]. Additionally, we compared the FAO's commodities list with a priority commodity list from one of the key tropical countries in this study as a reference: Indonesia's Ministry of Agriculture Strategic Plan [39]; we found that these lists intersect. Substantially, we will exclude tropical rainforest agriculture whose activities are in the form of livestock, aquaculture, pasture, mariculture, silvofishery, urban agriculture, riparian ecosystem agriculture, and agriculture producing biofuel, medicine, timber, fiber, and fodder.

Relevant tropical rainforest types: We will include studies that investigated agriculture and food crop production in tropical rainforests or equatorial rainforests or humid forests. Within this scope, we will incorporate studies ranging from pristine forests or naturally grown forests adjacent to agroecosystems. Moreover, as the types of natural ecosystems in the tropics are ample, of interest, we will focus only on the terrestrial part in which the classification follows differentiation based on physical (i.e., soil, climate, and altitude) and physiognomic characteristics. These include lowland evergreen rainforest, semievergreen rainforest, lower montane rainforest, and upper montane rainforest in tropical countries [40, 41]. The distinguishing characteristics of these rainforest ecosystem subtypes are summarized in Table 5 .

Regarding the spatial scale, we considered including a local (field or farm) landscape. This was suggested by previous research that investigated the effects of agriculture on biodiversity at multiple scales [42, 43] and based on discussion with Indonesian biology experts.

\section{Relevant exposures, comparators, and outcomes}

As we will assess bidirectional interactions between agriculture and biodiversity, we will generate two maps: (1) evidence of agriculture towards biodiversity (or Map 1) and (2) evidence of biodiversity towards agriculture (or Map 2). Therefore, we will have two sets of relevant exposures, comparators, and outcomes as follows:

(1) Evidence of agriculture towards biodiversity (Map 1).

Relevant exposures: For exposure, we will include indicators and sub-indicators of the tropical agricultural production base (environmental factors and genetic resources), land conversion, socioeconomic interactions, disturbances, and management of soil, pests, and 
Table 5 Four types of rainforest ecosystems distinguished by the altitude and physiognomy of the vegetation layer [40, 41]

\begin{tabular}{|c|c|c|}
\hline Rainforest types & Altitude & Physiognomic properties \\
\hline Lowland evergreen rainforest & From sea level to $1200 \mathrm{~m}$ & $\begin{array}{l}\text { Thick closed-canopy stands. Evergreen trees in a minimum of } 3 \text { layers. } \\
\text { Canopy surpassing } 30 \mathrm{~m} \text {. Emergent layer surpassing } 45 \mathrm{~m} \text { in height. } \\
\text { Lack of plant species diversity. Rare floor vegetation and are domi- } \\
\text { nated by tree seedlings }\end{array}$ \\
\hline \multicolumn{3}{|l|}{ Montane rainforest } \\
\hline Lower & Altitude range is $1200-1500 \mathrm{~m}$ & $\begin{array}{l}\text { Canopy is more equal. Lower statured compared to lowland evergreen. } \\
\text { Canopy height } 15-33 \mathrm{~m}\end{array}$ \\
\hline Upper & Altitude range is $1500-4000 \mathrm{~m}$ & $\begin{array}{l}\text { Smallest in stature. Emergent trees maximum } 26 \mathrm{~m} \text {. Canopy height from } \\
1.5 \text { to } 18 \mathrm{~m}\end{array}$ \\
\hline Semi-evergreen rainforest & $\begin{array}{l}\text { From the sea level to approximately } 1000 \text { m. } \\
\text { Strongly influenced by a yearly humidity } \\
\text { level }\end{array}$ & $\begin{array}{l}\text { Tall closed-canopy. Canopy and emergent heights are less than lowland } \\
\text { evergreen. Emergent vegetation can reach } 45 \mathrm{~m} \text { in height }\end{array}$ \\
\hline
\end{tabular}

water in the agroecosystem. In addition, a farming system that entails the scale of land ownership (smallholders and large holders) and crop diversification (monoculture and polyculture) will be included. We will exclude an integrated agricultural system (i.e., livestock combined with cropland), greenhouse agriculture, organic agriculture, hydroponics, verticulture, and silviculture. Further details on the framework-selected agricultural exposures included in this study are shown in Table 2. In terms of the spatial scale, we will cover studies that assess agricultural practices not only on a field and farm basis but also on a multilevel scale such as subnational, national, and regional scales.

Relevant comparators: The comparator includes a spatial and temporal comparator. Spatial comparator in empirical or experimental studies comprises of land with or without the agricultural interventions, and studies comparing natural or secondary forest versus farms with the interventions. Furthermore, studies comparing the similar type of crop agriculture in different locations (field, region, or country) will also be considered. The comparisons include different agroecosystem management methods applied by farmers (e.g., soil tillage vs chemical fertilizer amendment, polyculture with timber vs spice trees, pest management with natural fallows vs planted fallows, etc.). Temporal comparators examine the difference in outcomes before and after an agricultural intervention.

Relevant outcomes: Following the agricultural exposures that we will examine in this study, we will include the changes in biodiversity indicators (e.g., species richness and abundance) in the agroecosystems and natural ecosystems as the outcomes (see Table 2).

(2) Evidence of biodiversity towards agriculture (Map 2)

Relevant exposures: For the opposing relations, the focus of exposure would be biodiversity elements that offer services or disservices to agriculture. These will include environmental factors and genetic resources. It also comprises indicators of flora and fauna influencing agricultural production consisting of aboveground and soil biodiversity. The former includes plants that provide shelter, microhabitat, and litter sources. Invasive species, pollinators, and pest predators will also be included. Soil biodiversity consists of decomposers. Additionally, relevant spatial scales for exposure are at a multilevel scale because, in the TABF, we clearly distinguish biodiversity in the agroecosystem and natural ecosystem surrounding the farmland.

Relevant comparators: We will compare farms with more or less biodiversity mediating functionality.

Relevant outcomes: Changes of tropical agricultural production base (i.e., availability of edaphic and climatic factors, and availability and suitability of crop varieties) and changes in suitability of the agroecosystem management (i.e., management of soil, water, pest, and crop diversification) (Table 3).

\section{Relevant study designs}

The articles that will be included are grounded empirical studies employing qualitative, quantitative, or a combination of both types. Extensively, we will also consider studies of systematic reviews, reviews, and research that use experimental, quasi-experimental, and empirical modeling methods. Finally, we will exclude studies conducted using theoretical or nonempirical modeling studies, solely qualitative research, philosophical, conceptual, editorials, and books.

\section{Study validity assessment}

A systematic map of evidence does not require any formal validity and quality assessment for the included papers [33]. However, these assessments are necessary if subset research in the form of a systematic review is 
conducted. Since our main research intention is to create a systematic map, we will not apply study validity assessment considering the anticipated volume of studies we may collect. However, we will record the information related to the study context (in situ or ex situ) and study type/design (observational or experimental) of the included articles. We acknowledge that this will likely impair and limit our interpretations of the evidence map; therefore, we will communicate this limitation as part of our final report.

\section{Data coding strategy}

As required in RepOrting standards for Systematic Evidence Syntheses (ROSES, Additional file 4), a predesigned data collection coding sheet was made prior to the study (Additional file 5) and will be filled during the data extraction stage. The coding tool was developed based on similar studies $[15,44]$ with adjustments to meet our needs. To anticipate a large number of articles needed to be extracted, one person is assigned to extract one article. Furthermore, to ensure that this conduct still maintains the CEE standards and equally ensures consistency among reviewers, cross-checking towards the number of samples of extracted articles will be carried out. However, any resulting discrepancy encountered among the reviewers from this cross-checking will be addressed, discussed, and agreed upon for consistency. The data extracted from each study will include the following information:

- Source of publication

- Bibliographical information

- Publication type

- Study content

- Geographic location of the study

- Rainforest type

- Exposure type

- Outcome type

- Farm produce

- Study design

- Type of comparator

- Farm ownership

\section{Study mapping and presentation}

The visual representation of the maps in two structured matrices of the evidence depicting the bidirectional relationships between agricultural management and biodiversity aspects will be established. This approach will allow us to highlight the areas of studies with plentiful evidence or the lack thereof. Moreover, a descriptive statistical analysis to encapsulate the key characteristics and depict the trends along with the narrative synthesis will be performed. The key characteristic presentations will depend on the articles that pass the screening but presumably contain information about the population, exposures, outcomes, countries of study, and types of commodities examined.

\section{Supplementary Information}

The online version contains supplementary material available at https://doi. org/10.1186/s13750-021-00233-z.

Additional file 1. Search strings tested in Scopus.

Additional file 2. List of publications in the test library that meet the inclusion criteria.

Additional file 3. List of agricultural priority commodities in tropical rainforests countries.

Additional file 4. ROSES for systematic map protocols. Version 1.0.

Additional file 5. Coding sheet for Map 1 and Map 2.

\section{Acknowledgements}

Experts in biology and agriculture from Indonesia and the UK who attended the series of discussion on framework development for the planned evidence map.

\section{Authors' contributions}

SM conceived the idea of a systematic map study and secured funding support. All authors provided conceptual and technical information on the scope of the study and design of the search strategy. VA developed inclusion/ exclusion criteria with input from MH, FO, SM, and CS. CS implemented and refined the search strategy with inputs from $M H, F O$, and VA. VA, CS, MH, and FO developed the data coding strategy. Further, FO will coordinate the data mapping process, analysis, mapping presentation, and narrative synthesis. VA, $\mathrm{MH}, \mathrm{FO}$, and CS co-wrote the manuscript. All authors read and approved the final manuscript.

\section{Funding}

Bilateral Fund from the World Resources Institute (grant: 50076.03). This research has received grants from the Norwegian Ministry of Climate and Environment (KLD), through the World Resources Institute (WRI) Grant Partner No. RAL06, and from the World Resources Institute (WRI) Bilateral Fund No. 50076.03.

Availability of data and materials

The datasets used and/or analyzed during the current study are available from the corresponding author on reasonable request.

\section{Declarations}

Ethics approval and consent to participate Not applicable.

\section{Consent for publication}

Not applicable.

\section{Competing interests}

The authors declare that they have no competing interests.

\section{Author details}

${ }^{1}$ Research Center for Climate Change, Faculty of Mathematics and Natural Sciences, University of Indonesia, Depok, Indonesia. '2Department of Zoology, University of Oxford, Oxford, UK. ${ }^{3}$ Department of Tropical Biology, Faculty of Biology, Gadjah Mada University, Yogyakarta, Indonesia. ${ }^{4}$ World Resources Institute (WRI) Indonesia, Jakarta, Indonesia.

Received: 17 May 2021 Accepted: 29 July 2021

Published online: 03 September 2021 


\section{References}

1. D'annunzio R, Lindquist EJ, Macdicken KG. Global forest land-use change from 1990 to 2010: an update to a global remote sensing survey of forests. Rome, Italy: Food and Agriculture Organization of the United Nations (FAO). 2017. 14 p. Working paper No.: 187. http://foris.fao.org/ static/idf/RSS_2010update.pdf.

2. Latham J, Cumani R, Rosati I, Bloise M. Global land cover SHARE (GLCSHARE) database beta-release version 1.0. Rome, Italy: Food and Agriculture Organization of the United Nations (FAO). 2014.40 p. http://www. fao.org/uploads/media/glc-share-doc.pdf.

3. Gardner TA, Barlow J, Chazdon R, Ewers RM, Harvey CA, Peres CA, et al. Prospects for tropical forest biodiversity in a human-modified world. Ecol Lett. 2009;12(6):561-82

4. Sodhi NS, Koh LP, Clements R, Wanger TC, Hill JK, Hamer KC, et al. Conserving Southeast Asian forest biodiversity in human-modified landscapes. Biol Conserv. 2010;143(10):2375-84.

5. Balmford A, Green R, Phalan B. What conservationists need to know about farming. Proceed Biol Sci. 2012;279(1739):2714-24.

6. Carrasco LR, Webb EL, Symes WS, Koh LP, Sodhi NS. Global economic trade-offs between wild nature and tropical agriculture. PLoS Biol. 2017;15(7):e2001657.

7. Mayaux P, Holmgren P, Achard F, Eva H, Stibig H-J, Branthomme A. Tropical forest cover change in the 1990s and options for future monitoring. Philos Trans R Soc Lond B Biol Sci. 2005;360(1454):373-84.

8. Norgrove L, Beck J. Biodiversity function and resilience in tropical agroforestry systems including shifting cultivation. Curr For Rep. 2016;2(1):62-80.

9. Brancalion PHS, Niamir A, Broadbent E, Crouzeilles R, Barros FSM, Almeyda Zambrano AM, et al. Global restoration opportunities in tropical rainforest landscapes. Sci Adv. 2019;5(7):1-12.

10. Brandon K. Ecosystem services from tropical forests: review of current science. CGD Work Pap 380. 2014:Washington, DC: Venter for Global Development.

11. Mokany K, Westcott DA, Prasad S, Ford AJ, Metcalfe DJ. Identifying priority areas for conservation and management in diverse tropical forests. PLoS One. 2014;9(2):e89084.

12. Strassburg BBN, Iribarrem A, Beyer HL, Cordeiro CL, Crouzeilles R, Jakovac CC, et al. Global priority areas for ecosystem restoration. Nature. 2020;586:724-9.

13. Laurance WF, Sayer J, Cassman KG. Agricultural expansion and its impacts on tropical nature. Trends Ecol Evol. 2014;29(2):107-16.

14. Hoekstra AY, Mekonnen MM. The water footprint of humanity. Proc Natl Acad Sci. 2012:109(9):3232-7.

15. van der Meer M, Kay S, Lüscher $G$, Jeanneret P. What evidence exists on the impact of agricultural practices in fruit orchards on biodiversity? A systematic map. Environ Evid. 2020;9(1):2.

16. Power AG. Ecosystem services and agriculture: tradeoffs and synergies. Philos Trans R Soc B Biol Sci. 2010;365(1554):2959-71.

17. Borah JR, Laumonier Y, Bayala ERC, Djoudi H, Gumbo D, Moombe KB, et al. The role of biodiversity in integrated landscape approach. In: Reed J, Ros-Tonen M, Sunderland T, editors., et al., Operationalizing integrated landscape approaches in the tropics. Bogor: CIFOR; 2020

18. Hilje L, Araya CM, Valverde BE. Pest management in Mesoamerican agroecosystems. In: Vandermeer JH, editor. Tropical agroecosystems. Florida: CRC Press LLC; 2003. p. 267.

19. Andres C, Bhullar GS. Sustainable intensification of tropical agro-ecosystems: need and potentials. Front Environ Sci. 2016;4:5.

20. Gibbs HK, Ruesch AS, Achard F, Clayton MK, Holmgren P, Ramankutty N, et al. Tropical forests were the primary sources of new agricultural land in the 1980s and 1990s. Proc Natl Acad Sci. 2010;107(38):16732-7.

21. Organization for economic cooperation and development. Agriculture and Biodiversity: developing indicators for policy analysis. Zurich, Switzerland: OECD; 2001. p. 279.

22. Zhang W, Ricketts TH, Kremen C, Carney K, Swinton SM. Ecosystem services and dis-services to agriculture. Ecol Econ. 2007:64(2):253-60.

23. Lewis O. Biodiversity change and ecosystem function in tropical forests. Basic Appl Ecol. 2009:1(10):97-102

24. Klein A-M, Vaissière BE, Cane JH, Steffan-Dewenter I, Cunningham SA, Kremen C, et al. Importance of pollinators in changing landscapes for world crops. Proc R Soc B Biol Sci. 2007;274(1608):303-13.

25. Porto RG, de Almeida RF, Cruz-Neto O, Tabarelli M, Viana BF, Peres $C A$, et al. Pollination ecosystem services: a comprehensive review of economic values, research funding and policy actions. Food Secur. 2020;12(6):1425-42.

26. Roubik DW. Food and agriculture organization of the United Nations. Pollinator safety in agriculture. Rome, Italy: Food and Agriculture Organization of the United Nations (FAO). 2014. https://www.worldcat.org/title/ pollinator-safety-in-agriculture/oclc/893895435.

27. Brawn JD. Implications of agricultural development for tropical biodiversity. Trop Conserv Sci. 2017;10:1940082917720668.

28. Wilcove DS, Giam X, Edwards DP, Fisher B, Koh LP. Navjot's nightmare revisited: logging, agriculture, and biodiversity in Southeast Asia. Trends Ecol Evol. 2013;28(9):531-40.

29. Scherr SJ, MCNeely JA. Biodiversity conservation and agricultural sustainability: towards a new paradigm of'ecoagriculture' landscapes. Philos Trans R Soc B Biol Sci. 2008;363(1491):477-94.

30. Mumbunan S, Oktalira FT, Holle MJM, Apriyani V, Susanti R, Buchori D, Supriatna J. A framework for agriculture and biodiversity linkages in tropical rainforest landscape. Forthcoming in WRI Working Paper. World Resources Institute: Washington, DC. 2021.

31. Morales FJ. Introduction to tropical agriculture and outlook for tropical crops in a globalized economy. In: Claro KD, Oliveira PS, Rico-Gray V, editors. Tropical biology and conservation management, vol. 3. France: EOLSS; 2009.

32. Shin S, Soe KT, Lee H, Kim TH, Lee S, Park MS. A systematic map of agroforestry research focusing on ecosystem services in the Asia-Pacific Region. Forests. 2020;11(4):368

33. Collaboration for environmental evidence. Guidelines and standards for Evidence synthesis in Environmental Management. Version 5.0 (AS Pullin, GK Frampton, B Livoreil \& G Petrokofsky, Eds). 2018. http://www.envir onmentalevidence.org/information-for-authors.

34. Hopewell S, Mcdonald S, Clarke M, Egger M. Grey Literature in metaanalyses of randomized trials of health care interventions. Cochrane Database Syst Rev. 2007;2:MR000010.

35. Haddaway N, Bayliss H. Shades of grey: two forms of grey literature important for reviews in conservation. Biol Conserv. 2015;21:191.

36. Bramer WM, Giustini D, Kramer BMR, Anderson PF. The comparative recall of Google Scholar versus PubMed in identical searches for biomedical systematic reviews: a review of searches used in systematic reviews. Syst Rev. 2013;2(1):115.

37. Cheng SH, Augustin C, Bethel A, Gill D, Anzaroot S, Brun J, DeWilde B, Minnich RC, Garside R, Masuda YJ, Miller DC. Using machine learning to advance synthesis and use of conservation and environmental evidence. Conserv Biol. 2018:32(4):762-4.

38. FAOSTAT Statistical databases. Food and agriculture organization of the United Nations. http://faostat.fao.org/. Accessed: 2020 Dec 11.

39. Indonesian Ministry of Agriculture. Decree of the Minister of Agriculture of the Republic of Indonesia Number 259/Kpts/RC.020/M/05/2020 concerning the Strategic Plan of the Ministry of Agriculture 2020-2024. 2020. $176 \mathrm{p}$.

40. Whitmore TC. An introduction to tropical rainforests. 2nd ed. Oxford: Clarendon Press; 1998. p. 296.

41. Armstrong AH. Tropical rainforest ecosystems. International Encyclopedia of Geography. 2018;p. 1-16.

42. Gabriel D, Sait SM, Hodgson JA, Schmutz U, Kunin WE, Benton TG. Scale matters: the impact of organic farming on biodiversity at different spatial scales. Ecol Lett. 2010;13(7):858-69.

43. Bengtsson J, Ahnström J, Weibull A-C. The effects of organic agriculture on biodiversity and abundance: a meta-analysis. J Appl Ecol. 2005:42(2):261-9.

44. Sordello R, Flamerie De Lachapelle F, Livoreil B, Vanpeene S. Evidence of the environmental impact of noise pollution on biodiversity: a systematic map protocol. Environ Evid. 2019;8(1):8.

\section{Publisher's Note}

Springer Nature remains neutral with regard to jurisdictional claims in published maps and institutional affiliations. 